Article

\title{
Implementation of Non-Destructive Electrical Condition Monitoring Techniques on Low-Voltage Nuclear Cables: I. Irradiation Aging of EPR/CSPE Cables
}

\author{
Ehtasham Mustafa ${ }^{1,2}{ }^{\mathbb{D}}$, Ramy S. A. Afia ${ }^{2,3} \mathbb{D}$, Oumaima Nouini ${ }^{2}$ and Zoltán Ádám Tamus ${ }^{2, *(\mathbb{D})}$ \\ 1 Department of Electrical Engineering, Gomal University, Dera Ismail Khan 29050, Pakistan; \\ mustafa.ehtasham@vet.bme.hu \\ 2 Department of Electric Power Engineering, Budapest University of Technology and Economics, \\ H-1111 Budapest, Hungary; ramysaad@h-eng.helwan.edu.eg (R.S.A.A.); omaima.nouini@gmail.com (O.N.) \\ 3 Department of Electrical Power \& Machines Engineering, Helwan University, Cairo 11792, Egypt \\ * Correspondence: tamus.adam@vik.bme.hu
}

\section{check for}

updates

Citation: Mustafa, E.; Afia, R.S.A.; Nouini, O.; Tamus, Z.Á.

Implementation of Non-Destructive Electrical Condition Monitoring

Techniques on Low-Voltage Nuclear Cables: I. Irradiation Aging of EPR/CSPE Cables. Energies 2021, 14, 5139. https://doi.org/10.3390/ en14165139

Academic Editor: Guglielmo Lomonaco

Received: 23 July 2021

Accepted: 18 August 2021

Published: 20 August 2021

Publisher's Note: MDPI stays neutral with regard to jurisdictional claims in published maps and institutional affiliations.

Copyright: (c) 2021 by the authors. Licensee MDPI, Basel, Switzerland. This article is an open access article distributed under the terms and conditions of the Creative Commons Attribution (CC BY) license (https:/ / creativecommons.org/licenses/by/ $4.0 /)$.

\begin{abstract}
In a nuclear power plant environment, low-voltage cables experience different stresses during their service life which challenge their integrity. A non-destructive and reliable condition monitoring technique is desired to determine the state of these low-voltage cables during service and for the life extension of nuclear power plants. Hence, in this research work, an EPR/CSPEbased low-voltage cable was exposed to $\gamma$-rays for five different absorbed doses. The overall behavior of the cable under stress was characterized by frequency and time domain electrical measurements (capacitance, $\tan \delta$, and Extended Voltage Response) and a mechanical measurement (elongation at break). Significant variations in the electrical parameters were observed, as was a decline in the elongation at break values. A strong correlation between the measurement methods was observed, showing the ability of the electrical methods to be adopted as a non-destructive condition monitoring technique.
\end{abstract}

Keywords: nuclear power plant; low-voltage cables; radiation aging; dielectric spectroscopy; extended voltage response; elongation at break

\section{Introduction}

This paper is a continuation of the work published in papers focusing on the investigation and implementation of non-destructive condition monitoring (CM) techniques for low-voltage (LV) nuclear power plant (NPP) cables [1,2]. According to the latest report from the International Atomic Energy Agency (IAEA) [3], many NPPs are designed to operate for 30-40 years, with some evidence of aging being underestimated not only during original design but also during operation. Hence, aging management of the structure, systems, and components is adopted for the safe and reliable operation of NPPs [4,5]. For effective aging management, condition monitoring (CM) and trending of aging effects are generic aspects. LV cables are components deployed in NPPs to supply power and control signals to equipment related to the plant's safety.

The LV cables in NPPs are vulnerable to degradation during service, and they are exposed to several stresses such as radiation, elevated temperature, electrical and mechanical stresses [6]. The presence of chemicals such as lubricants and ozone also affects the degradation process. The insulation and jacket of the cables are based on polymer materials and on a combination of different additives and fillers to improve their mechanical, electrical, and fire-retardant properties. Among the multiple stressors, radiation stress with the presence of oxygen gives a peculiar aspect to the degradation problem as the molecular structure of the polymer is affected significantly; hence, the macroscopic properties of the polymer are influenced, a topic which has been investigated for many years in different aspects [7-10]. 
The variation in the mechanical properties of the polymer insulation due to aging is evident. Therefore, elongation at break $(\mathrm{EaB})$ as a $\mathrm{CM}$ technique is generally used to determine the end of life of the insulation [11,12]. Nevertheless, the implementation of $\mathrm{EaB}$ as an online $\mathrm{CM}$ technique is limited due to its destructive nature. For the reliable operation of the cable, the electrical properties of the polymeric insulation are an important characteristic $[13,14]$. In recent times, significant variation in the electrical properties of different materials due to aging has been studied using different techniques such as Line Resonance Analysis (LIRA), dielectric spectroscopy, and Time-Domain Reflectometry (TDR) [8,12,15-17]. Most of the research has been focused on determining the state of the insulation and the jacket of the cable separately. However, a need for studying and monitoring the condition of the overall cable without separating the insulation and jacket is inevitable. Additionally, the establishment of the correlation of the electrical results with the mechanical tests is still needed. Likewise, the response of the dielectric properties due to the aging mechanism such as crosslinking, chain scission, and oxidation is a topic that still needs to be explored, as different materials will show different behaviors due to their proprietary composition.

Hence, this work is focused on ethylene-propylene rubber (EPR)-insulated and chlorosulphonated polyethylene (CSPE)-jacketed-based instrumentation and control (I\&C) cables. These are widely used insulation and jacket types in the NPP environment [18]. The whole cable was subjected to accelerated radiation aging for five different absorbed doses. The electrical properties were explored in two domains: frequency and time, i.e., capacitance and $\tan \delta$ as frequency and Extended Voltage Response (EVR) as time. At the same time, $\mathrm{EaB}$ was investigated to determine the mechanical integrity of the insulation. Where electrical aging markers from the electrical tests were selected, a correlation was established with the mechanical test results.

Henceforth, the paper aims to outline the aging of the cable's polymer components without separating them, using different diagnostic techniques, and establish the correlation of degradation with the selected aging markers. The non-destructive electrical test results contribute to implementing non-destructive techniques for assessing cable aging in the NPP environment.

\section{Materials and Methods}

\subsection{Cable Specimen}

The LV cable under study, shown in Figure 1, was designed for I\&C applications. The two-core cable had inner EPR insulation, with the thickness of the insulation being $0.76 \mathrm{~mm}$ and the radius of the conductor $0.732 \mathrm{~mm}$. The outer jacket of the cable was composed of CSPE with an external diameter of $12.5 \mathrm{~mm}$. The cable was designed for a $90^{\circ} \mathrm{C}$ maximum operating temperature. The cable was manufactured by JS Cable Co. Ltd. (Seoul, Korea), for the Class 1E application. For the investigation, five half-meter-long samples were prepared.

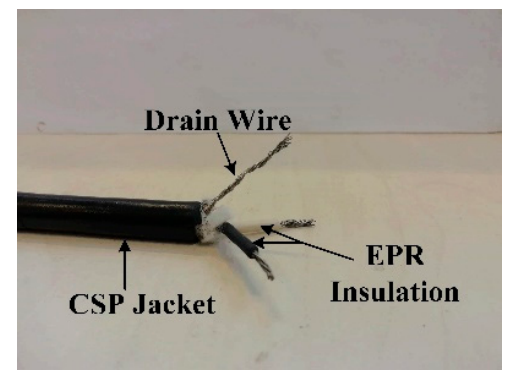

Figure 1. Cable sample under consideration.

\subsection{Accelerated Radiation Aging}

The $\gamma$-ray ${ }^{60} \mathrm{Co}$ accelerated radiation aging was carried out at the Institute of Isotopes

Co. Ltd. (Budapest, Hungary). Five cable samples were used for the study, and the 
absorbed dose for each sample was 120 kGy, 360 kGy, 600 kGy, 840 kGy, and 1200 kGy, respectively. The absorbed doses correspond to the service times of $16,48,80,113$, and 162 years considering the normal service dose, which does not exceed $1 \mathrm{~Gy} / \mathrm{h}$ [4]. The cable samples were irradiated with a $0.8 \mathrm{kGy} / \mathrm{h}$ dose rate under a temperature of $25^{\circ} \mathrm{C}$, with continuous ventilation preventing ozone accumulation.

\subsection{Measurement}

\subsubsection{Capacitance and $\tan \delta$}

The measurement of capacitance and $\tan \delta$ was carried out in two frequency ranges with two different devices. The detail of the frequency domain measurement setup is given in Table 1.

Table 1. Experimental setup of dielectric spectroscopy.

\begin{tabular}{ccc}
\hline Device & Frequency Range & Input Voltage \\
\hline Omicron Dirana & $10 \mathrm{mHz}-1 \mathrm{kHz}$ & $100 \mathrm{~V}_{\mathrm{rms}}$ \\
Wayne Kerr Component Analyzer & $2 \mathrm{kHz}-500 \mathrm{kHz}$ & $5 \mathrm{~V}_{\mathrm{rms}}$ \\
\hline
\end{tabular}

The $\tan \delta$ is described by the relation [19]:

$$
\tan \delta=\mathrm{I}_{\mathrm{R}} / \mathrm{I}_{\mathrm{C}}=\varepsilon^{\prime \prime} / \varepsilon^{\prime},
$$

where the $\tan \delta$ is based on the principle of the measurement of the angle between the resistive current and capacitive current in the insulation when an external AC electric field with a given frequency is applied [20], as shown in Figure 2. With the increase in impurities or defects, the resistive component will increase, increasing the $\tan \delta$. The variation of the $\tan \delta$ with sweeping frequency gives a wide range of information on the insulation [21,22].

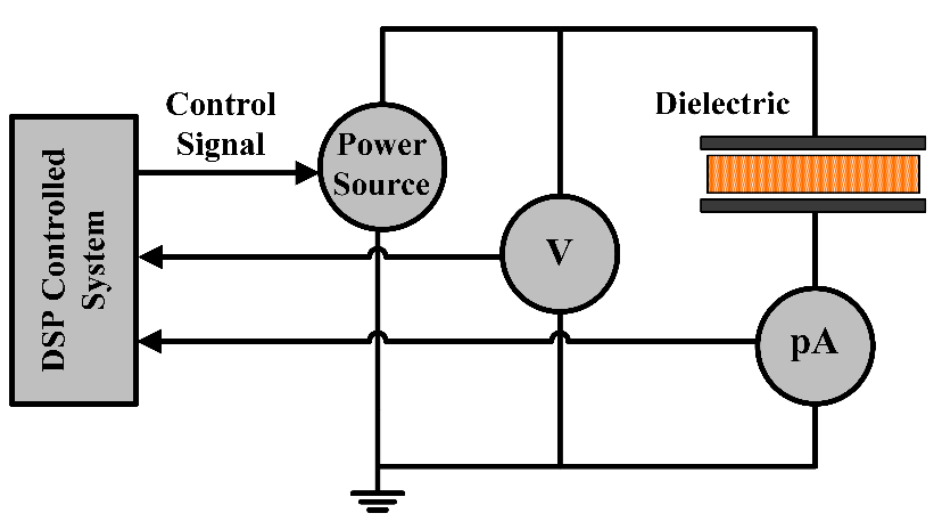

(a)

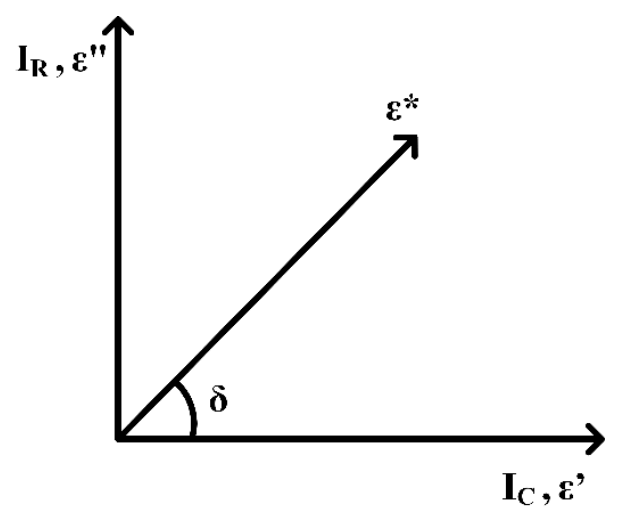

(b)

Figure 2. (a) Circuit construction of $\tan \delta$, (b) $\tan \delta$ vector diagram.

Figure 3a shows the setup for the OMICRON Dirana, while Figure $3 b$ shows the setup for the Wayne Kerr Component Analyzer. For the insulation measurement, the input signal was applied to the cable conductor, while the output signal was obtained through the drain wire. At the same time, the jacket and the other core conductor were shorted. For the measurement of the jacket, the outer surface of the cable was covered with an aluminum foil of $29 \mathrm{~cm}$ in length forming the outer electrode. The input signal was applied to this foil electrode while the drain acted as a source of the output signal. The insulation cores were left open circuited during this measurement. For both measurements, the cable sample was placed in a Faraday cage to avoid any external noise interference. However, for the OMICRON Dirana setup, a guard connection was also used. 


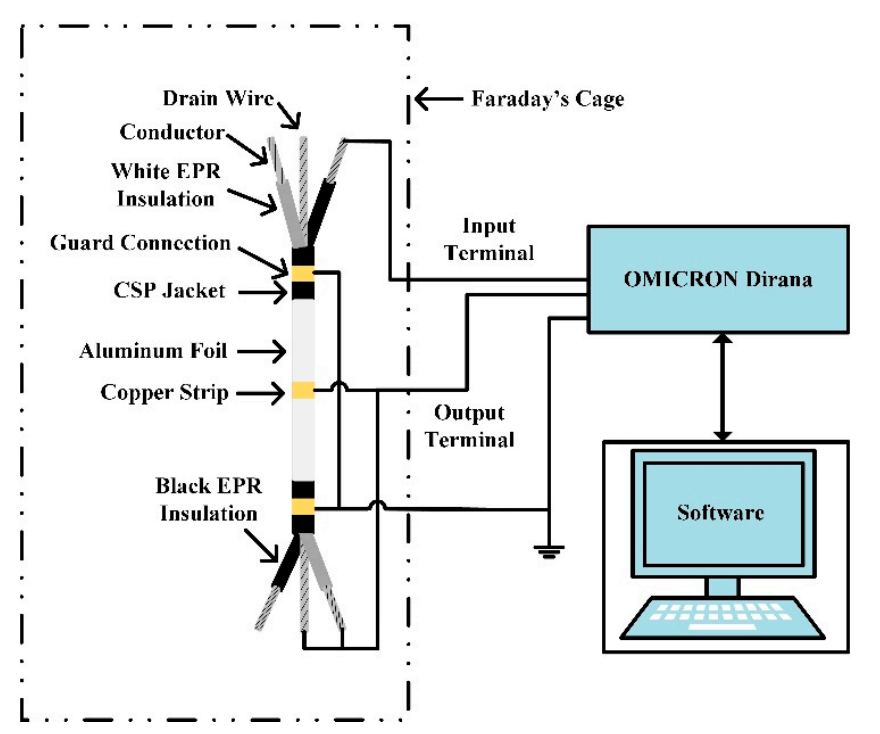

(a)

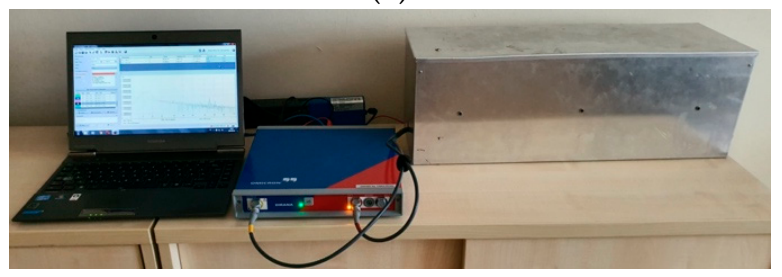

(c)

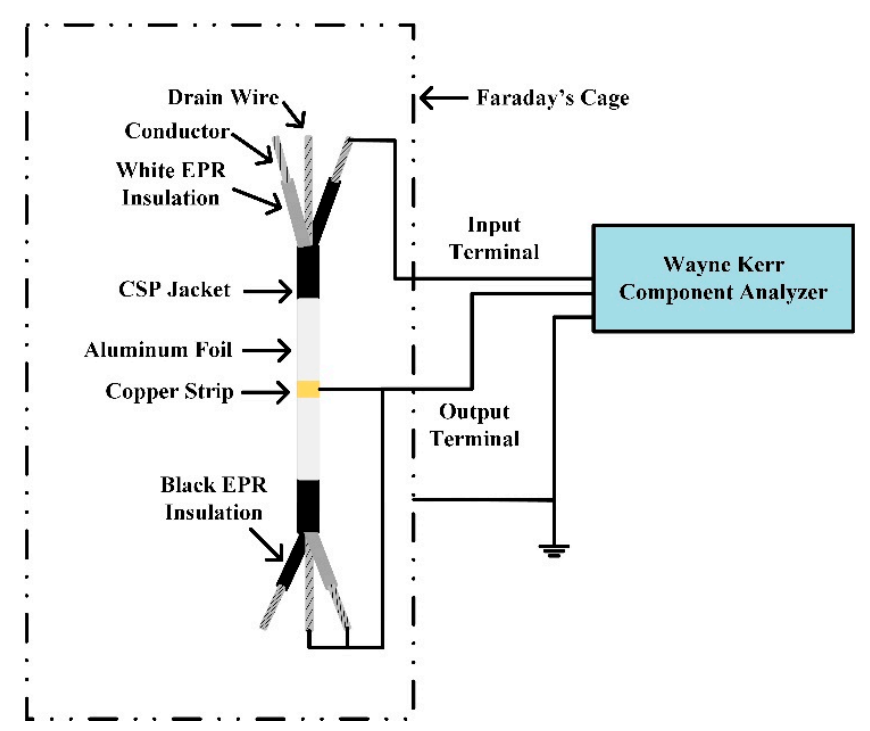

(b)

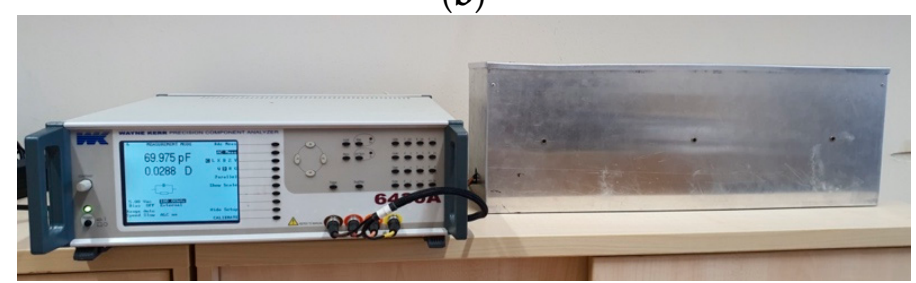

(d)

Figure 3. Capacitance and $\tan \delta$ measurement setup: (a) OMICRON Dirana, (b) Wayne Kerr Component Analyzer and photos of equipment, (c) OMICRON Dirana, (d) Wayne Kerr Component Analyzer.

\subsubsection{Extended Voltage Response}

To study the slow dielectric polarization processes in electrical insulation, EVR was used for the investigation. In the last few years, the EVR technique has been adopted for aging investigations in electrical insulating materials ranging from high-voltage to lowvoltage applications [23,24]. The detailed working of the EVR can be found elsewhere [1,2].

The cable insulation was charged for $4000 \mathrm{~s}$ with a DC voltage source of $1000 \mathrm{~V}$. With the disconnection of the voltage source, the slope of decay voltage $\left(S_{d}\right)$ was estimated. After discharging, another parameter, the slope of return voltage $\left(\mathrm{S}_{\mathrm{r}}\right)$, can be measured. This parameter was measured for 20 different discharging times and plotted as a function of discharging time. The $S_{d}$ is proportional to the conductivity, while the $S_{r}$ is proportional to the intensity of polarization processes. Figure 4 shows the measuring arrangement of the EVR for the cable samples. All the electrical measurements were carried out at $25 \pm 0.5^{\circ} \mathrm{C}$.

\subsubsection{Elongation at Break}

According to the IEC/IEEE 62582-3 standard [25], elongation at break (EaB) was measured on six tubular samples from unaged and each radiation-dosed insulation sample. The measurements were carried out at room temperature on a universal mechanical testing machine (Instron 5566). 


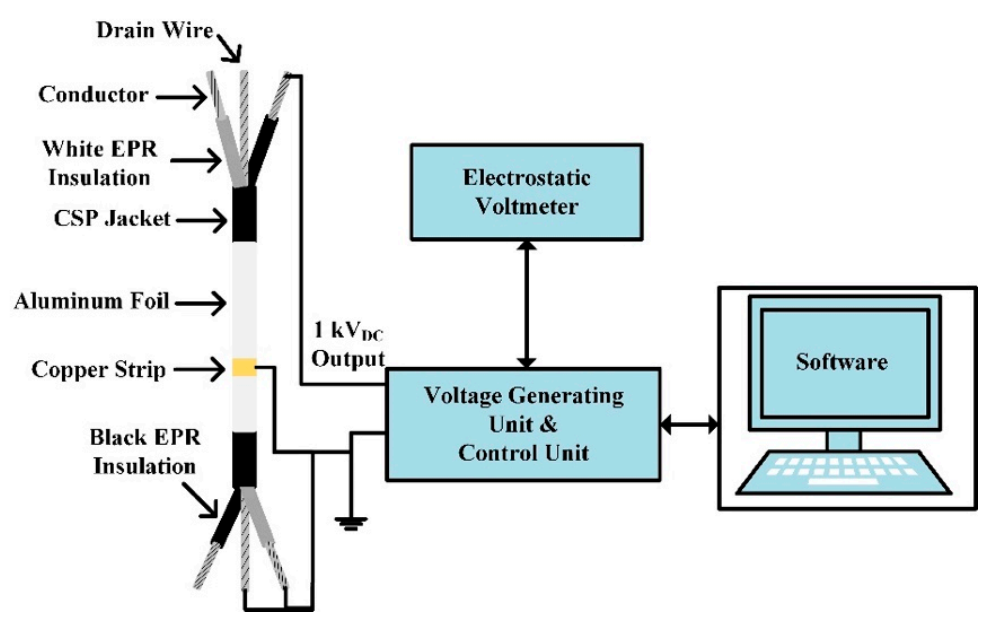

(a)

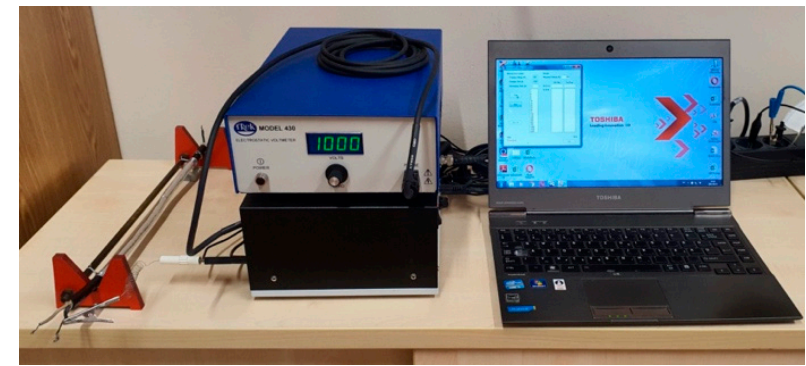

(b)

Figure 4. Extended Voltage Response (EVR) measurement: (a) setup and (b) a photo of the equipment.

\section{Results}

\subsection{Capacitance and $\tan \delta$}

Figure 5 shows the results of the capacitance of the polymeric materials for the two frequency ranges. Figure $5 \mathrm{a}, \mathrm{b}$ have been plotted for the EPR insulation, while Figure $5 \mathrm{c}, \mathrm{d}$ are for the CSPE jacket. An increase in the whole low-frequency range was observed for EPR and CSPE with each absorbed dose. In the high-frequency range, except for a decrease in capacitance after the first absorbed dose, an increase was observed with the increase in the absorbed dose for both polymeric materials.

The $\tan \delta$ results for the low- and high-frequency ranges are plotted in Figure 6 for EPR insulation and the CSPE jacket. For the case of EPR insulation, as for the low-frequency range, the $\tan \delta$ starting with a high value at the minimum frequency decreased with the increase in the frequency, reaching its minimum value at a certain frequency, and then started to increase. In contrast, for the high-frequency range, the tan $\delta$ had the minimum value at the lowest frequency, i.e., $2 \mathrm{kHz}$, and then increased with the sweeping of the frequency and then reached the maximum value at $500 \mathrm{kHz}$. The effect of the absorbed dose on the EPR insulation was observed as an increase in the $\tan \delta$ values at all frequency points.

However, the $\tan \delta$ for the CSPE jacket showed a different characteristic trend for frequency variation. For the low-frequency range, the $\tan \delta$ started with a low value at $10 \mathrm{mHz}$ and then continued to increase, reaching its maximum value at $40 \mathrm{mHz}$. As the frequency was swept, the $\tan \delta$ values started to decline, reached their minimum value at $200 \mathrm{~Hz}$, and then increased. The effect of the absorbed dose on the overall $\tan \delta$ values of the jacket was observed as an increase in its values. However, for the first three absorbed doses, the peak of the tan $\delta$ shifted from the lower frequency, $40 \mathrm{mHz}$, to a higher frequency, i.e., $200 \mathrm{mHz}$. In the last two absorbed doses, the peak shifted to the lowest frequency, i.e., $10 \mathrm{mHz}$. The minimum value of the curve also shifted to the highest frequency, i.e., $1 \mathrm{kHz}$ with each absorbed dose.

In contrast, for the high-frequency case, the $\tan \delta$ values for the unaged sample had the lowest value at the lowest frequency and started to increase, reaching its peak at the highest frequency point. With each absorbed dose, this trend was altered as a lower peak was observed at a certain frequency after having a higher value at the lowest frequency. This lower peak was observed to shift to higher frequencies as the absorbed dose increased. However, the $\tan \delta$ values showed an overall increase in their values with each absorbed dose for the high-frequency range. 


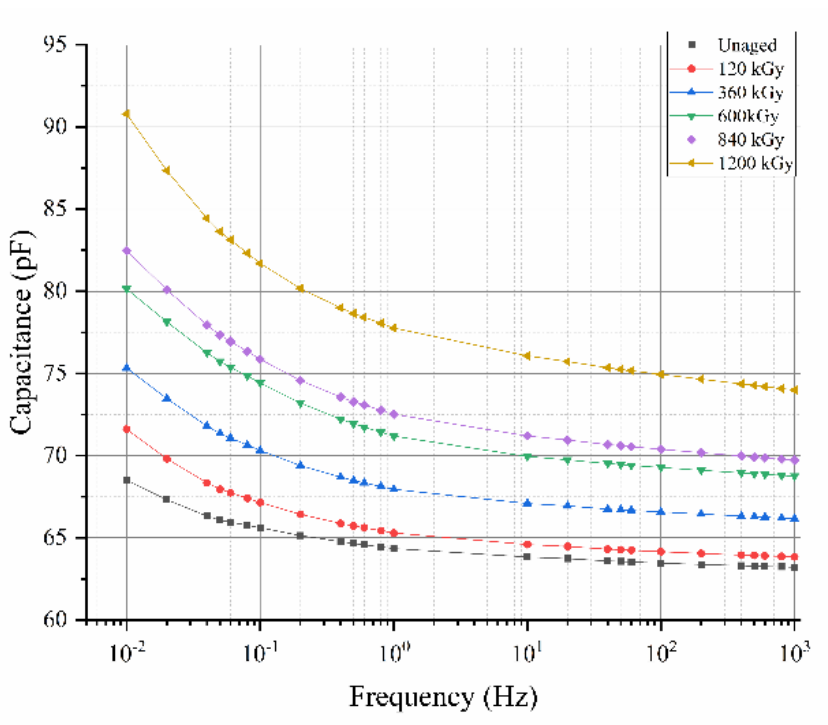

(a)

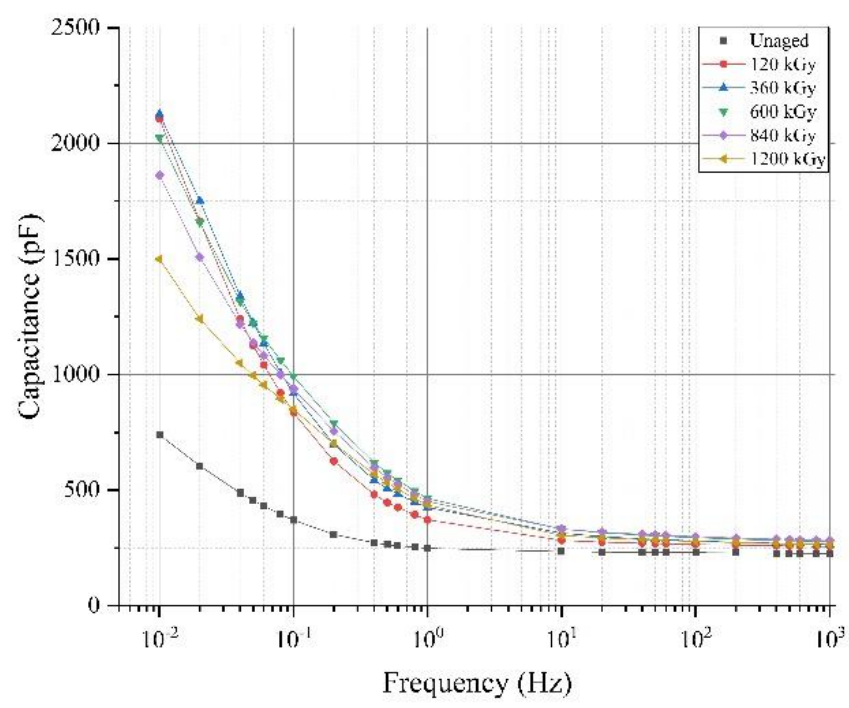

(c)

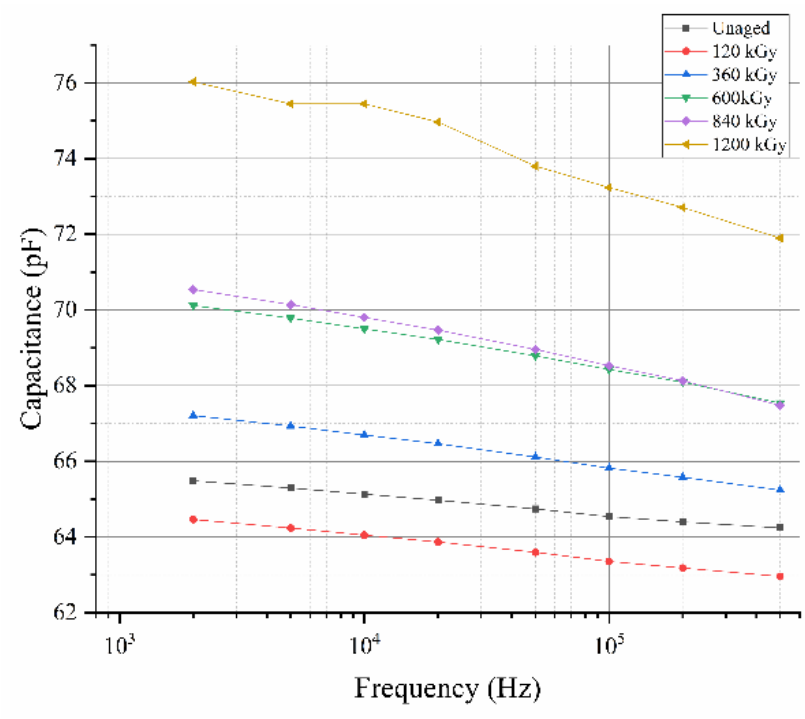

(b)

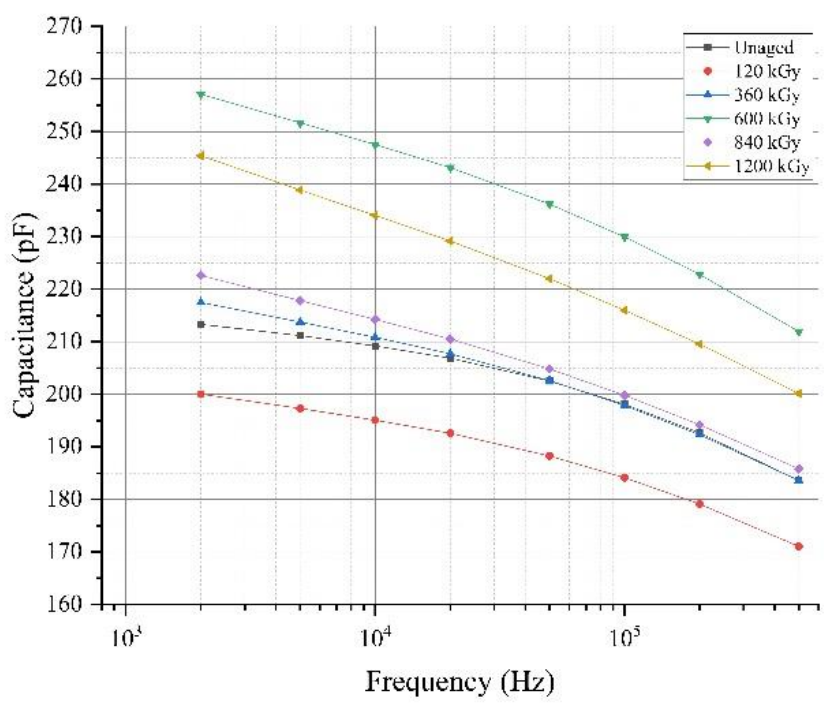

(d)

Figure 5. Capacitance vs. frequency. EPR insulation: (a) $10 \mathrm{mHz}$ to $1 \mathrm{kHz}$, (b) $2 \mathrm{kHz}$ to $500 \mathrm{kHz}, \mathrm{CSPE}$ jacket: (c) $10 \mathrm{mHz}$ to $1 \mathrm{kHz},(\mathbf{d}) 2 \mathrm{kHz}$ to $500 \mathrm{kHz}$ for different absorbed doses. 


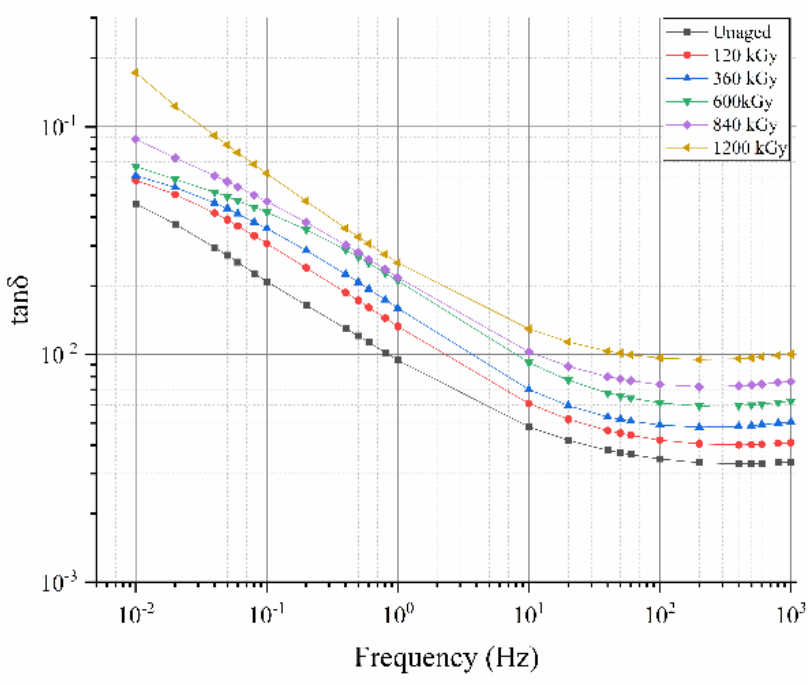

(a)

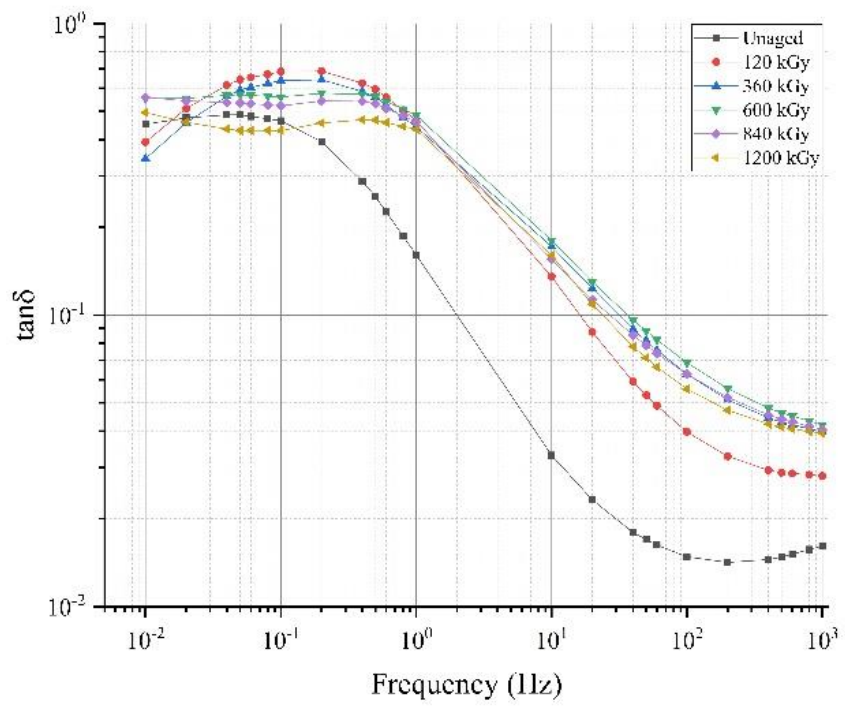

(c)

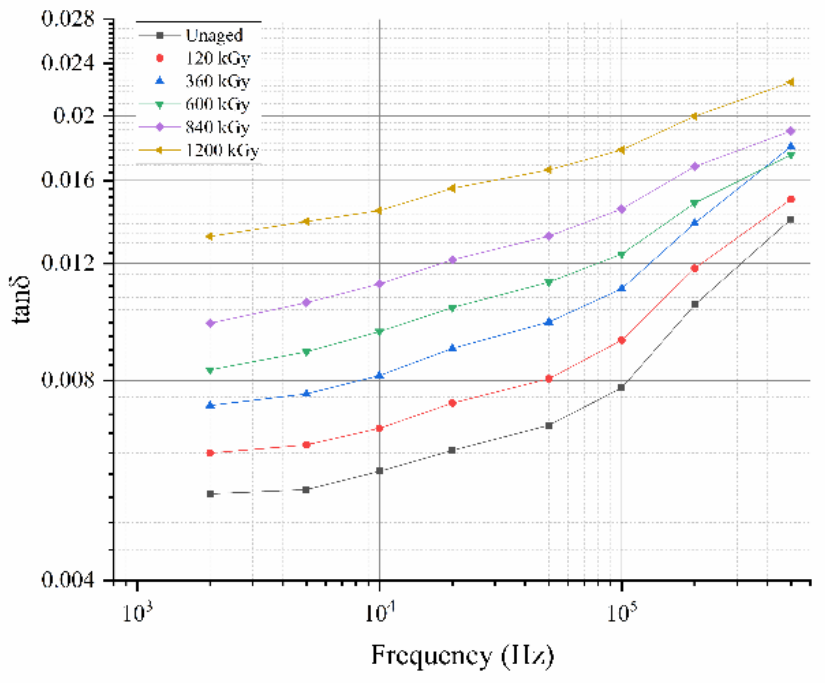

(b)

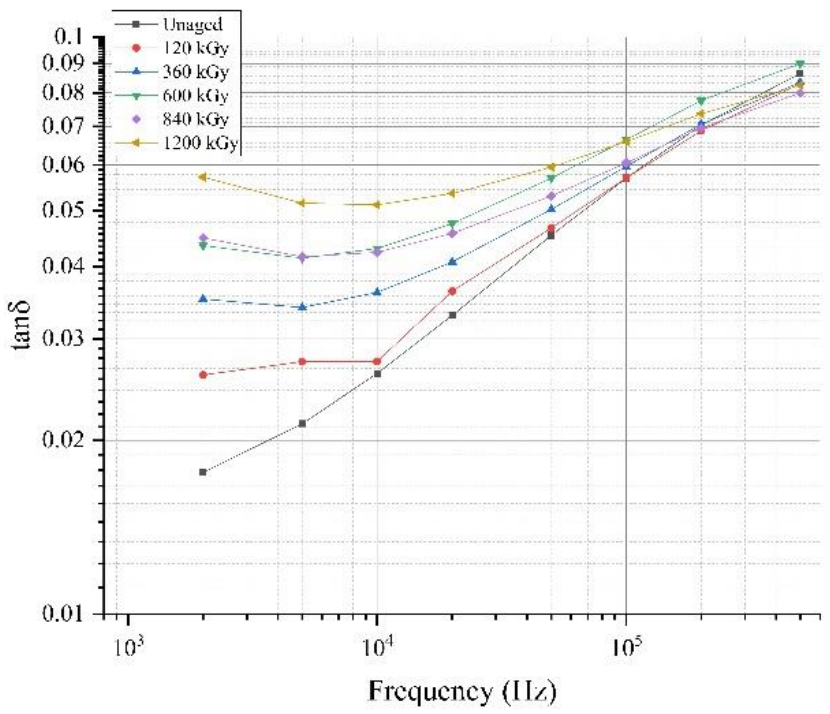

(d)

Figure 6. $\tan \delta$ vs. frequency. EPR insulation: (a) $10 \mathrm{mHz}$ to $1 \mathrm{kHz}$, (b) $2 \mathrm{kHz}$ to $500 \mathrm{kHz}, \mathrm{CSPE}$ jacket: (c) $10 \mathrm{mHz}$ to $1 \mathrm{kHz}$, (d) $2 \mathrm{kHz}$ to $500 \mathrm{kHz}$ for different absorbed doses.

\subsection{Extended Voltage Response}

The EVR results of the EPR insulation and CSPE jacket are plotted in Figure 7. The decay voltage slope $\left(\mathrm{S}_{d}\right)$ for the insulation and jacket increased as the absorbed dose increased, as shown in Figure 7a,c. Similarly, the return voltage slope $\left(\mathrm{S}_{\mathrm{r}}\right)$ also increased at all 20 discharging times with each absorbed dose, as shown in Figure $7 \mathrm{~b}$ for the EPR insulation. The variation of return voltage slopes, especially at low (around $10^{-1} \mathrm{~V} / \mathrm{s}$ ) values, was due to environmental electromagnetic noise. 


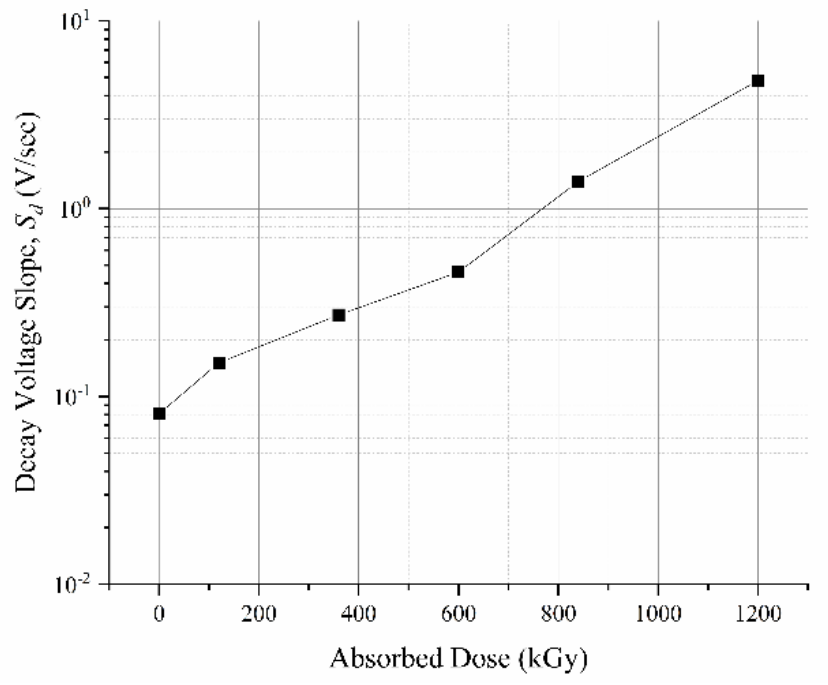

(a)

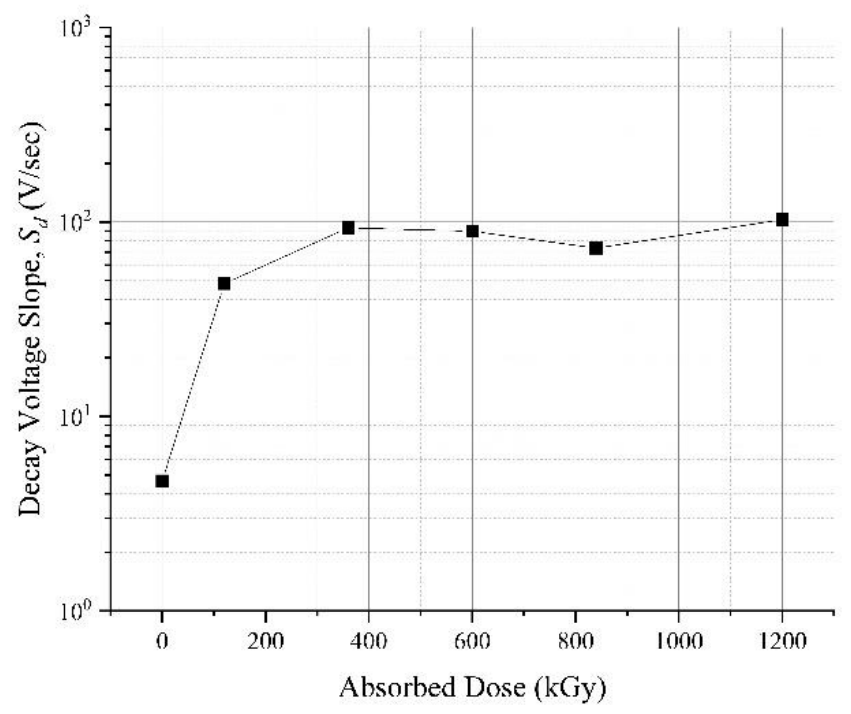

(c)

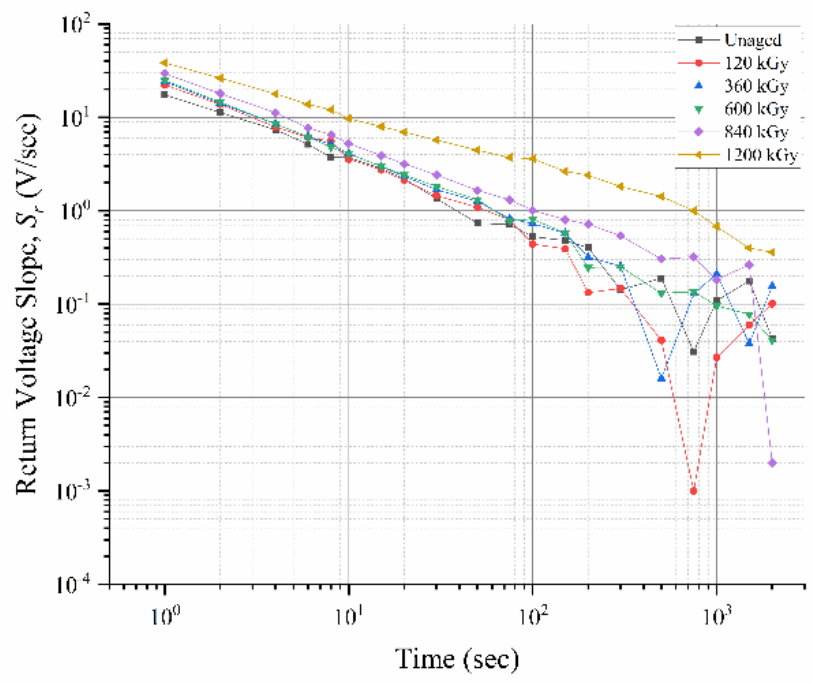

(b)

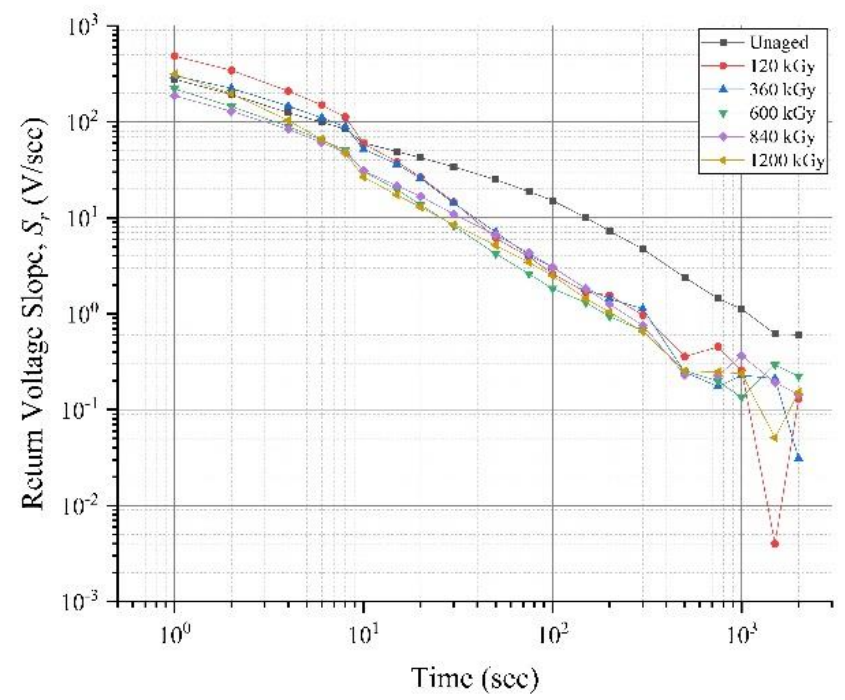

(d)

Figure 7. EVR measurement. EPR insulation: (a) $S_{d}$ vs. absorbed dose (kGy), (b) $S_{r}$ vs. discharging time for a different absorbed dose, CSPE jacket: (c) $S_{d}$ vs. absorbed dose (kGy), (d) $S_{r}$ vs. discharging time for different absorbed doses.

However, the return voltage slope for the CSPE jacket showed different behavior compared to the EPR insulation, as shown in Figure 7d. The return voltage slope increased after the first absorbed dose, which then decreased until the fourth absorbed dose period, and then increased until the final absorbed dose period.

\subsection{Elongation at Break}

The EaB measurement results of the EPR insulation and CSPE jacket are plotted in Figure $8 \mathrm{a}, \mathrm{b}$. The EaB constantly decreased for both polymeric materials with the increase in the absorbed dose. However, a significant decrease was noticed after the second dose period for the insulation compared to the jacket, where after the second radiation dose period, an abrupt reduction in the $\mathrm{EaB}$ was observed, which was less than $50 \%$ relative to the unaged one. For the jacket, a 50\% reduction in the EaB was observed after the third radiation dose period. 


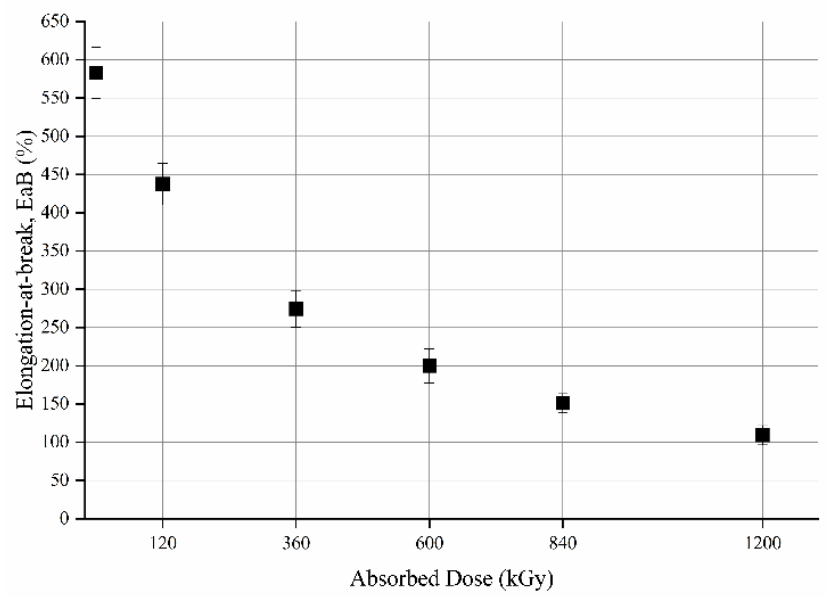

(a)

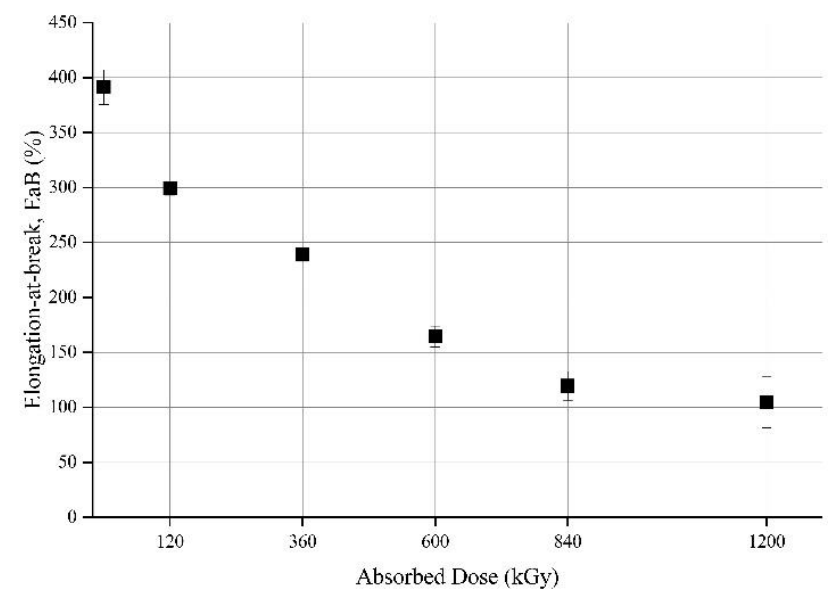

(b)

Figure 8. Elongation at break against different absorbed doses (kGy): (a) EPR insulation, (b) CSPE jacket.

\section{Discussion}

Since the response of the EPR insulation and CSPE jacket to the irradiation showed different behaviors in the electrical and mechanical tests, the discussion will henceforth be carried out on the insulation and jacket separately.

\subsection{EPR Insulation}

As reported in the literature, when EPR is irradiated in the presence of oxygen, it undergoes a series of reactions. This process is initiated with free radical generation, followed by the formation of intermediate peroxide products due to cross-linking and oxidation reactions. Then, the generation of carbonyl, carboxylate, and ether function groups follows, reflecting the polymer chains' degradation [26].

These radical groups in the presence of an external electric field will respond to it according to their respective time constants. Since the frequency range adopted for the investigation was between $10 \mathrm{mHz}$ and $500 \mathrm{kHz}$, the frequency below $100 \mathrm{~Hz}$ was associated with interfacial polarization, known as Maxwell-Wagner-Sillars, and between $100 \mathrm{~Hz}$ and $100 \mathrm{kHz}$, dipolar polarization [27]. Interfacial polarization was caused by limited diffusion of the space charges into the dielectric under the electric field, and then they settled next to the chemical or physical interfaces. In contrast, the high-frequency range was related to dipolar species due to the oxidized polymer groups.

While analyzing the change in capacitance and $\tan \delta$ with reference to the unaged values at selected frequencies, i.e., $10 \mathrm{mHz}, 100 \mathrm{mHz}, 100 \mathrm{~Hz}, 1 \mathrm{kHz}, 100 \mathrm{kHz}$, and 500 $\mathrm{kHz}$, as shown in Figure 9, it was observed that after the first radiation dose, except at 100 $\mathrm{kHz}$ and $500 \mathrm{kHz}$ where a decrease in the capacitance was noticed, there was an increase in the capacitance. However, $\tan \delta$ showed an increasing trend at $100 \mathrm{kHz}$ and $500 \mathrm{kHz}$ after the first dose. This could be because there was competition between the physio-chemical reactions initially, i.e., crosslinking and chain scission. Otherwise, an increasing trend was observed in the capacitance and $\tan \delta$ values with exposure to larger doses. 


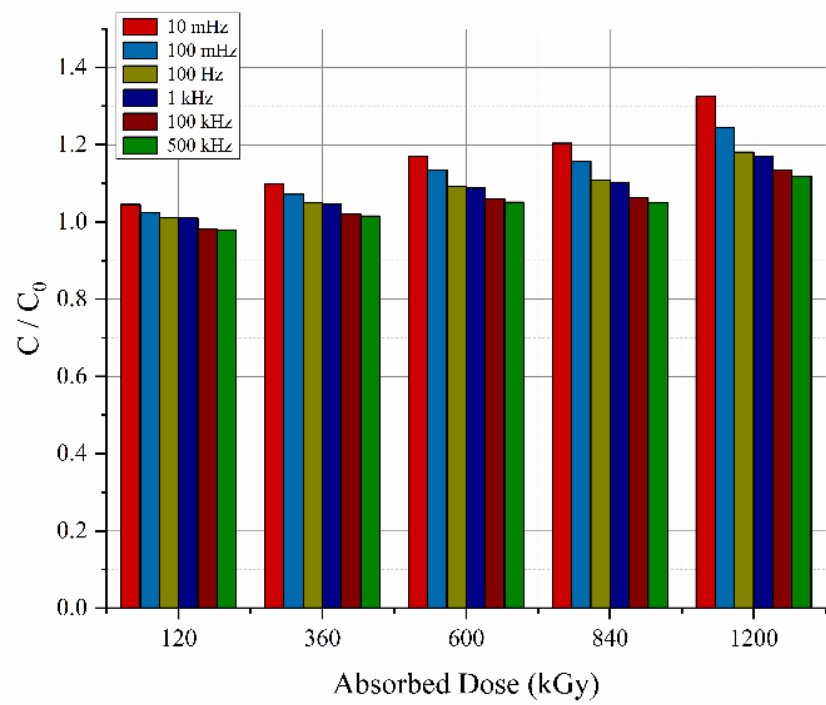

(a)

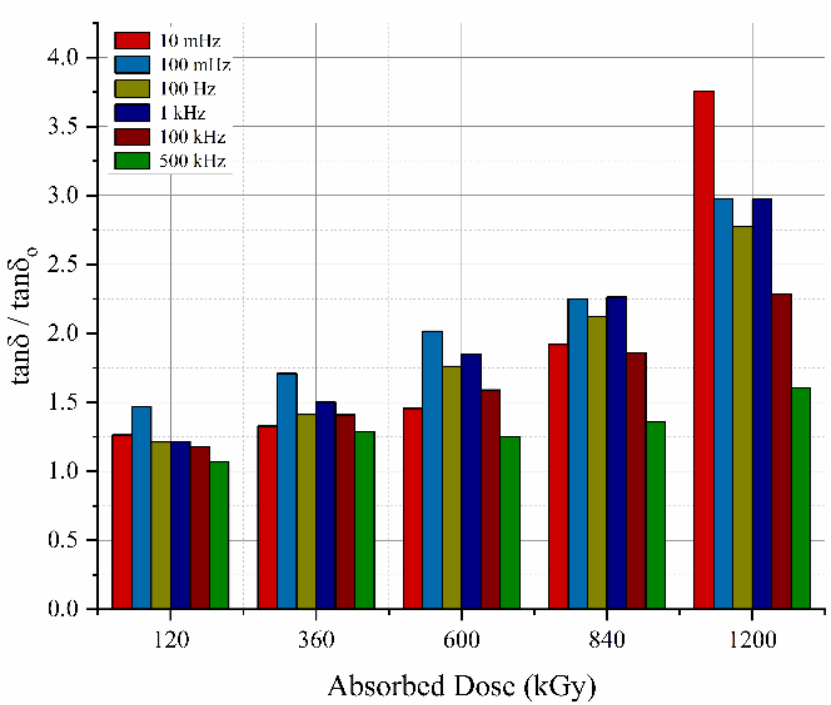

(b)

Figure 9. Change in: (a) capacitance, (b) tan $\delta$ for different absorbed dose (kGy) at $10 \mathrm{mHz}, 100 \mathrm{mHz}, 100 \mathrm{~Hz}, 1 \mathrm{kHz}$, $100 \mathrm{kHz}$, and $500 \mathrm{kHz}$ for EPR insulation.

These significant changes in the capacitance and $\tan \delta$ demonstrated the degradation of polymer chains, which resulted in the chemical species adding to interfacial and dipolar polarization as shown by the drastic increase in the values at $100 \mathrm{~Hz}$ and below at $100 \mathrm{kHz}$. The peaks in the high-frequency range were caused by the presence of dipolar species $[18,28,29]$. The dipolar nature of oxygen, which is bonded with radicals, results in the dipolar species, resulting in the increase in the $\tan \delta$ values at $100 \mathrm{kHz}$, which shows the role of the oxygen in the degradation of EPR during irradiation. The presence and strong influence of oxygen during irradiation on EPR have also been reported in the literature $[26,30,31]$.

Since the results of the EVR also showed a significant increase in the $S_{r}$, which defines slow polarization processes as interfacial, the increase in interfacial polarization is also supported by these results. For simplification, the $S_{\mathrm{r}}$ values measured at $1 \mathrm{~s}$ are plotted against the absorbed dose in Figure 10.

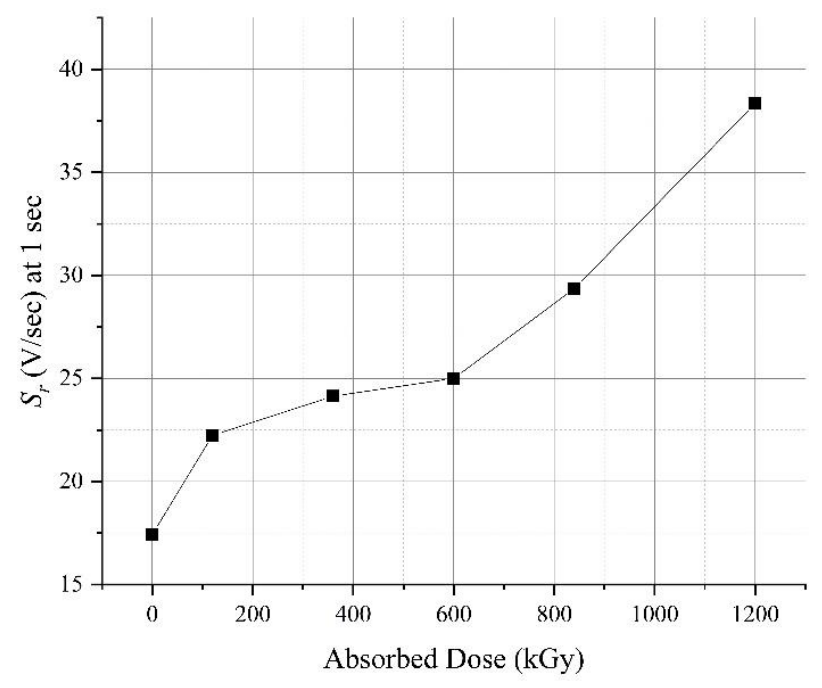

Figure 10. $S_{r}$ at $1 \mathrm{~s}$ variation against absorbed dose for EPR insulation. 
Very low frequencies such as $10 \mathrm{mHz}$ and $100 \mathrm{mHz}$ are influenced by charge transportation or conductivity. Charge transportation for non-polar polymers such as EPR is generally due to the presence of carbonyl groups. These groups, as mentioned, are generated due to the presence of oxygen and behave as shallow energy level traps [7]. When these charges accumulate in front of the electrode, they allow new charge carriers from the electrodes to eject in the polymer, which increases conductivity. This phenomenon is revealed by the increase in the $\tan \delta$ values at low frequencies and also in the $S_{d}$ values, where the $S_{d}$ is related to the conductivity.

The degradation of EPR's mechanical integrity due to exposure to irradiation was observed as embrittlement of the polymer. This degradation of the polymer was due to the permanent morphological changes that happened during aging.

\subsection{CSPE Jacket}

Like EPR, CSPE under irradiation experiences a series of reactions, i.e., cross-linking, chain scission, and oxidation. Apart from these reactions' chlorine loss, dehydrochlorination, a chain reaction [32-34], also occurs during irradiation. In the presence of oxygen, there is the formation of small molecular radicals and macromolecular radicals. Their mobility is different, as small molecular radicals have high mobility compared to macromolecular radicals, which have limited diffusion [34]. Under a low electric field, small molecular fragments (low molecular radicals) respond to the field as they have mobility, while macromolecular radical mobility is limited because they cannot diffuse far from where they were created. This phenomenon was observed, as a significant increase in the $\tan \delta$ values for frequencies below $1 \mathrm{kHz}$ was noticed, as shown in Figure 11. However, little variation in the $\tan \delta$ values at $100 \mathrm{kHz}$ suggests little presence of dipolar species and hence little influence of oxygen. These small molecular radicals also behave as shallow traps with low energy, enhancing conductivity or charge transportation. The results of the $\tan \delta$ at frequencies of $10 \mathrm{mHz}$ and $100 \mathrm{mHz}$ and $S_{d}$ indicate this phenomenon.

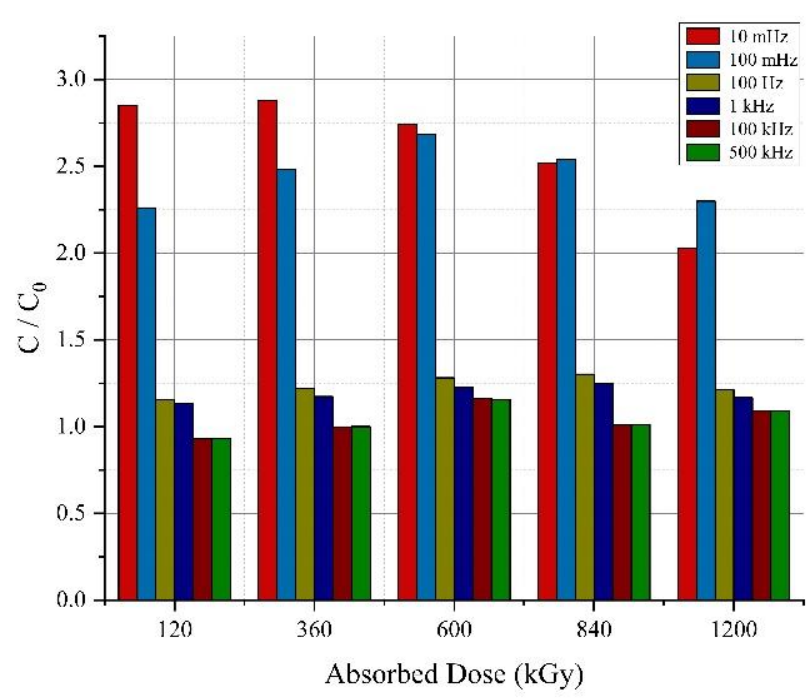

(a)

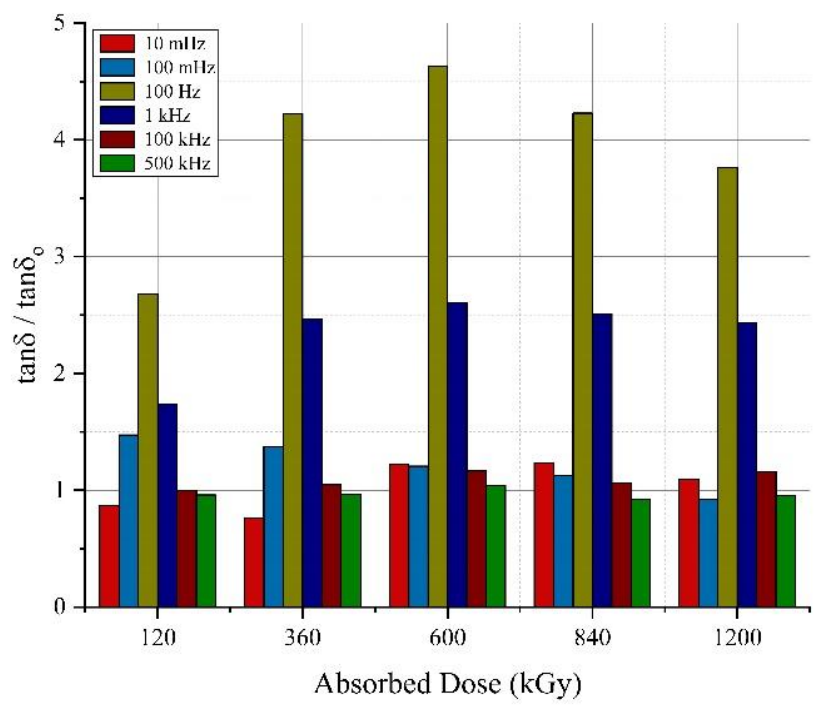

(b)

Figure 11. Change in: (a) capacitance, (b) $\tan \delta$ for different absorbed doses (kGy) at $10 \mathrm{mHz}, 100 \mathrm{mHz}, 100 \mathrm{~Hz}, 1 \mathrm{kHz}$, $100 \mathrm{kHz}$, and $500 \mathrm{kHz}$ for CSPE jacket.

The inconsistent behavior of the $S_{r}$ values at $1 \mathrm{~s}$ as shown in Figure 12, with radiation, indicates a parallel occurrence of a cross-linking reaction during irradiation. As the crosslinking reaction results in a three-dimensional network within the molecules, it restricts charge transportation mobility [35]. This can decrease the polarization conductivity and thus the $S_{r}$ value. 


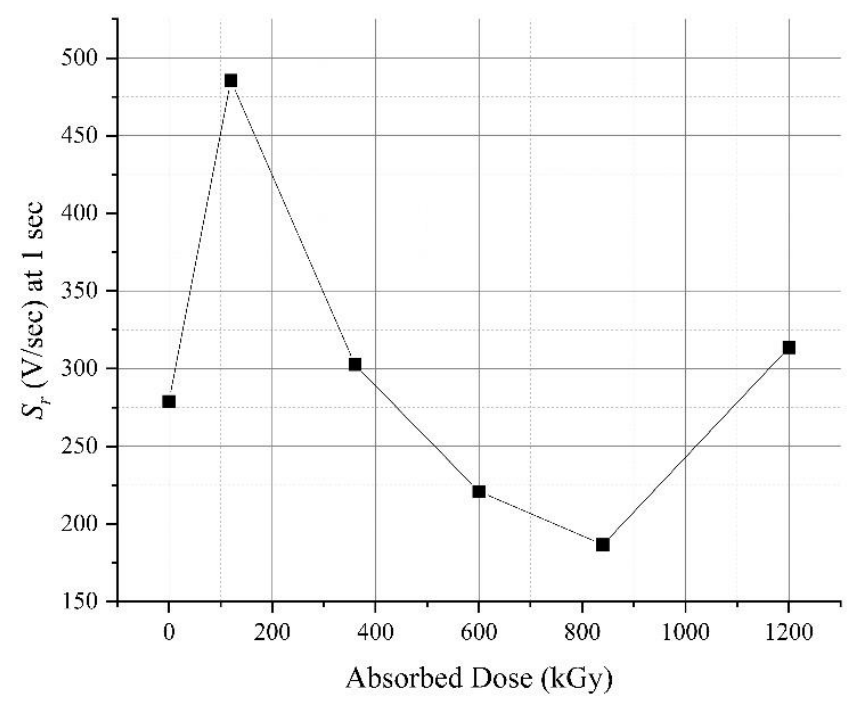

Figure 12. $S_{r}$ at $1 \mathrm{~s}$ variation against absorbed dose for CSPE jacket.

Furthermore, the decrease in EaB for CSPE occurred in a regular fashion, which was because the material became harder and more inflexible with aging time [36]. This showed the domination of the cross-linking reaction compared to chain scission, which is in agreement with previous observations made on CSPE [37,38]. Although the EaB for both EPR insulation and CSPE jacket decreased during aging, it was observed that the EPR insulation's 50\% decrease in the EaB happened earlier than for the jacket, as shown in Figure 13. This result shows that irradiation has a more degrading effect on EPR than on CSPE. A similar result has been observed for EPR, where an abrupt failure of mechanical properties was noticed in the presence of oxygen during aging [30].

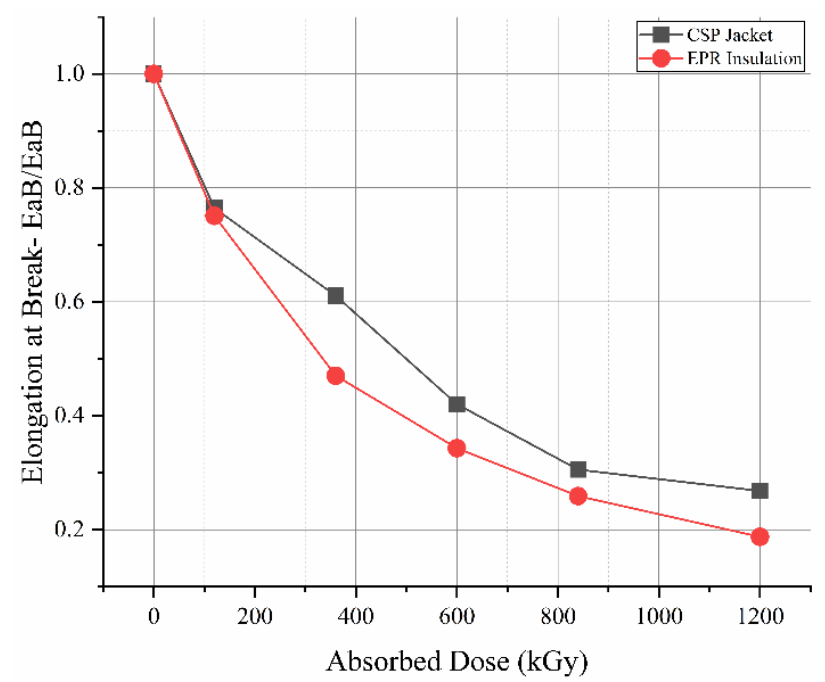

Figure 13. Change in elongation at break for EPR insulation and CSPE jacket.

\section{Correlation between Electrical and Mechanical Properties}

To select appropriate aging markers, the correlation values between $\mathrm{EaB}$ and the electrical parameters were determined by calculating the coefficient of determination $\left(R^{2}\right)$ for both the EPR insulation and CSPE jacket. Since the cable insulation is a complex, layered dielectric structure, and the dipolar polarization changes with aging, capacitance, and $\tan \delta$ values at lower $(10 \mathrm{mHz}$ and $100 \mathrm{mHz})$ and higher $(100 \mathrm{~Hz}, 1 \mathrm{kHz}$, and $100 \mathrm{kHz})$ frequencies were incorporated into correlation calculations. The change in conductivity and the intensity of slow polarization processes were investigated by the measured return voltage. The $S_{d}$ and $S_{r}$ values were also tested. Table 2 summarizes the results. As the 
table shows, a strong correlation was observed between the parameters for EPR insulation, especially in the case of $\tan \delta$ at $100 \mathrm{mHz}$ and higher frequencies. However, on the CSPE jacket, the $\mathrm{R}^{2}$ values were smaller. Tan $\delta$ at $100 \mathrm{~Hz}$ and higher frequencies seem applicable markers. It is important to note that the $S_{d}$ also had a high $R^{2}$, but the change in $S_{d}$ with absorbed dose was not monotonic. Hence, the correlation analysis provided a misleading result.

Table 2. Correlation values between $\mathrm{EaB}$ and different electrical quantities for EPR insulation and CSPE jacket.

\begin{tabular}{|c|c|c|c|}
\hline \multirow{2}{*}{\multicolumn{2}{|c|}{ Electrical Quantities }} & \multirow{2}{*}{$\begin{array}{c}\text { EPR } \\
\text { EaB } \\
\end{array}$} & \multirow{2}{*}{$\begin{array}{c}\text { CSPE } \\
\text { EaB }\end{array}$} \\
\hline & & & \\
\hline \multirow{2}{*}{$10 \mathrm{mHz}$} & Capacitance & 0.9729 & 0.2043 \\
\hline & $\tan \delta$ & 0.7994 & 0.3835 \\
\hline \multirow{2}{*}{$100 \mathrm{mHz}$} & Capacitance & 0.9729 & 0.6095 \\
\hline & $\tan \delta$ & 0.9582 & 0.1503 \\
\hline \multirow{2}{*}{$100 \mathrm{~Hz}$} & Capacitance & 0.9572 & 0.7707 \\
\hline & $\tan \delta$ & 0.9808 & 0.7194 \\
\hline \multirow{2}{*}{$1 \mathrm{kHz}$} & Capacitance & 0.9579 & 0.7515 \\
\hline & $\tan \delta$ & 0.9889 & 0.6333 \\
\hline \multirow{2}{*}{$100 \mathrm{kHz}$} & Capacitance & 0.8595 & 0.327 \\
\hline & $\tan \delta$ & 0.9906 & 0.6192 \\
\hline \multirow{2}{*}{\multicolumn{2}{|c|}{$\begin{array}{c}S_{d} \\
S_{r} \text { at } 1 \mathrm{~s}\end{array}$}} & 0.9435 & 0.7418 \\
\hline & & 0.9138 & 0.2354 \\
\hline
\end{tabular}

Thus, $\tan \delta$ at $100 \mathrm{kHz}$ and the $\mathrm{S}_{\mathrm{d}}$ have been selected as electrical aging markers and are plotted in log-log scale in Figure 14. As shown with the high $R^{2}$ values, the strong linear relationship makes the selected electrical aging markers suitable for detecting aging in the polymer alone, without parallel mechanical EaB tests.

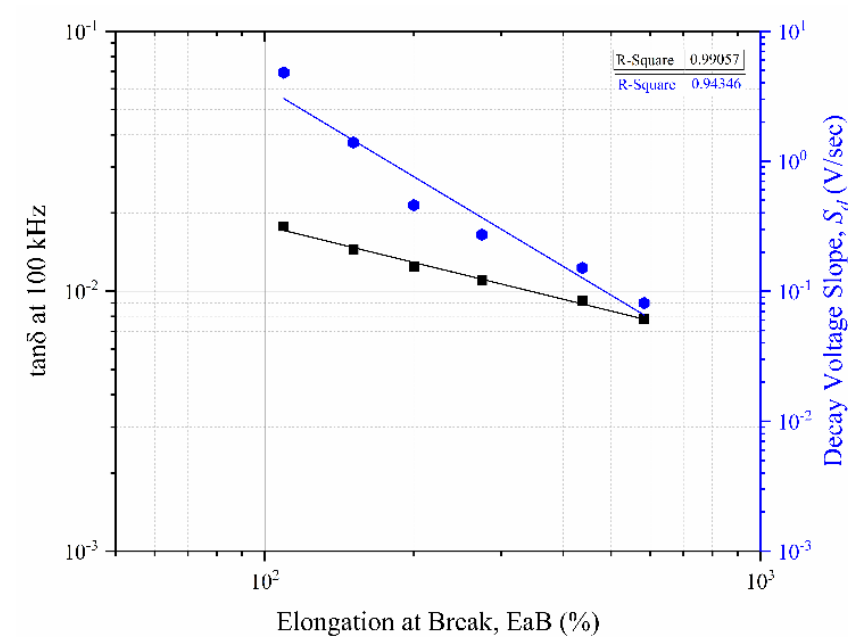

(a)

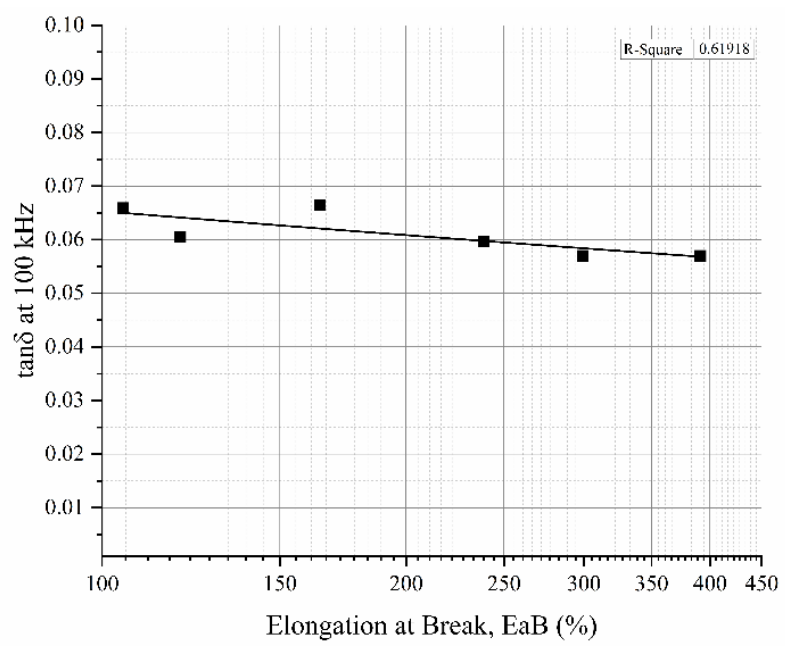

(b)

Figure 14. Correlation between elongation at break and (a) $\tan \delta$ at $100 \mathrm{kHz}$ and $\mathrm{S}_{\mathrm{d}}$ on EPR insulation, (b) $\tan \delta$ at $100 \mathrm{kHz}$ on CSPE jacket.

This result supports the findings of previous studies. On EPR and XLPE insulation, the imaginary part of permittivity measured at $100 \mathrm{kHz}$ has shown a strong correlation with density, EaB [11], absorbed dose [17], and aging time in the case of radio-thermal aging [8]. The dielectric loss increase at $1 \mathrm{MHz}$ was almost linear on XLPE insulation in combined thermal and radiation aging [18]. Similar results were observed for EPR insulation by dissipation factor measurements at $1 \mathrm{kHz}$ and $1 \mathrm{MHz}$ [10]. Higher dissipation 
factor values at $1 \mathrm{MHz}$ indicate that the relaxation peak is closer to this frequency than $1 \mathrm{kHz}$. In conclusion, the dielectric loss in the $100 \mathrm{kHz}$ to $1 \mathrm{MHz}$ range seems a sensitive marker of aging for NPP polymer cable insulation due to the change in dipolar polarization. Nevertheless, further investigations on different cable insulating polymers are necessary to reveal the direct relationship with the mechanical test, i.e., EaB results, to replace mechanical tests with dielectric ones.

\section{Conclusions}

This paper investigated the overall degradation of EPR/CSPE-based LV NPPs cable due to irradiation. The physio-chemical changes due to aging were studied by adopting two non-destructive electrical CM techniques. Significant changes in the capacitance and $\tan \delta$ at both low- and high-frequencies were observed for polymeric materials, suggesting enhanced dipolar polarization because of oxidation reactions and chain scission. An increase in the $S_{r}$ and $S_{d}$ values indicates that increased mobility of charge carriers resulted in intensive interfacial polarization.

A strong correlation between $\tan \delta$ at different frequencies and the $S_{d}, S_{r}$ and EaB was observed for EPR and CSPE, which enables the adaptation of electrical methods as non-destructive CM techniques for LV cables without separating the insulation and jacket. Further investigation with the aid of chemical tests such as oxidation induction time (OIT) and Fourier-Transform Infrared Spectroscopy (FTIR) is suggested, which will give an in-depth understanding of the effect of radiation stress at the lowest level. Additionally, the application of CM techniques for different types of LV NPP cables under different single and multiple stressors will further enhance their effectiveness and establish them for field measurements in NPP environments.

Author Contributions: Conceptualization, R.S.A.A., E.M., O.N. and Z.Á.T.; investigation R.S.A.A., O.N. and E.M.; formal analysis, E.M.; writing—original draft preparation, E.M.; visualization, E.M.; writing-review and editing, Z.Á.T.; supervision, Z.Á.T.; funding acquisition, Z.Á.T. All authors have read and agreed to the published version of the manuscript.

Funding: Project no. 123672 has been implemented with support provided by the National Research, Development, and Innovation Fund of Hungary, financed under the KNN_16 funding scheme.

Institutional Review Board Statement: Not applicable.

Informed Consent Statement: Not applicable.

Data Availability Statement: Not applicable.

Conflicts of Interest: The authors declare no conflict of interest.

\section{References}

1. Mustafa, E.; Afia, R.S.A.; Tamus, Z.A. Application of Non-Destructive Condition Monitoring Techniques on Irradiated Low Voltage Unshielded Nuclear Power Cables. IEEE Access 2020, 8, 166024-166033. [CrossRef]

2. Mustafa, E.; Afia, R.S.A.; Tamus, Z.Á. Dielectric loss and extended voltage response measurements for low-voltage power cables used in nuclear power plant: Potential methods for aging detection due to thermal stress. Electr. Eng. 2020. [CrossRef]

3. International Atomic Energy Agency. Ageing Management for Nuclear Power Plants: International Generic Ageing Lessons Learned (IGALL); Safety Reports Series No. 82 (Rev. 1); International Atomic Energy Agency: Vienna, Austria, 2020.

4. International Atomic Energy Agency. Benchmark Analysis for Condition Monitoring Test Techniques of Aged Low Voltage Cables in Nuclear Power Plants; International Atomic Energy Agency: Vienna, Austria, 2017.

5. Chang, Y.S.; Mosleh, A. Probabilistic model of degradation of cable insulations in nuclear power plants. Proc. Inst. Mech. Eng. Part. O J. Risk Reliab. 2019. [CrossRef]

6. Mustafa, E.; Afia, R.S.A.; Tamus, Z.Á. Condition Monitoring Uncertainties and Thermal-Radiation Multistress Accelerated Aging Tests for Nuclear Power Plant Cables: A Review. Period. Polytech. Electr. Eng. Comput. Sci. 2019, 64, 20-32. [CrossRef]

7. Chen, G.; Banford, H.M.; Davies, A.E. Influence of radiation environments on space charge formation in y-irradiated LDPE. IEEE Trans. Dielectr. Electr. Insul. 1999, 6, 882-886. [CrossRef]

8. Suraci, S.V.; Fabiani, D.; Xu, A.; Roland, S.; Colin, X. Ageing Assessment of XLPE LV Cables for Nuclear Applications through Physico-Chemical and Electrical Measurements. IEEE Access 2020, 8, 27086-27096. [CrossRef] 
9. Gao, Y.; Du, B.X. Effect of gamma-ray irradiation on permittivity and dielectric loss of polymer insulating materials. In Proceedings of the 2012 International Conference on High Voltage Engineering and Application, Shanghai, China, 17-20 September 2012; IEEE: Piscataway, NJ, USA, 2012; pp. 229-232. [CrossRef]

10. Shao, Z.; Byler, M.I.; Liu, S.; Bowler, N.; Fifield, L.S.; Murphy, M.K. Dielectric Response of Cross-Linked Polyethylene (XLPE) Cable Insulation Material to Radiation and Thermal Aging. In Proceedings of the 2018 IEEE 2nd International Conference on Dielectrics (ICD), Budapest, Hungary, 1-5 July 2018; pp. 1-4. [CrossRef]

11. Verardi, L.; Fabiani, D.; Montanari, G.C. Correlation of electrical and mechanical properties in accelerated aging of LV nuclear power plant cables. In Proceedings of the 2014 ICHVE International Conference on High Voltage Engineering and Application, Poznan, Poland, 8-11 September 2014; pp. 1-4. [CrossRef]

12. Verardi, L.; Fabiani, D.; Montanari, G.C. Electrical aging markers for EPR-based low-voltage cable insulation wiring of nuclear power plants. Radiat. Phys. Chem. 2014, 94, 166-170. [CrossRef]

13. Boukezzi, L.; Boubakeur, A. Effect of Thermal Aging on the Electrical Characteristics of XLPE for HV Cables. Trans. Electr. Electron. Mater. 2018, 19, 344-351. [CrossRef]

14. Chi, X.; Li, J.; Ji, M.; Liu, W.; Li, S. Thermal-oxidative aging effects on the dielectric properties of nuclear cable insulation. Materials 2020, 13, 2215. [CrossRef]

15. Ekelund, M.; Fantoni, P.F.; Gedde, U.W. Thermal ageing assessment of EPDM-chlorosulfonated polyethylene insulated cables using line resonance analysis (LIRA). Polym. Test. 2011, 30, 86-93. [CrossRef]

16. Lee, C.-K.; Kwon, G.-Y.; Shin, Y.-J. Condition Assessment of I\&C Cables in Nuclear Power Plants via Stepped-Frequency Waveform Reflectometry. IEEE Trans. Instrum. Meas. 2019, 68, 215-224. [CrossRef]

17. Linde, E.; Verardi, L.; Fabiani, D.; Gedde, U.W. Dielectric spectroscopy as a condition monitoring technique for cable insulation based on crosslinked polyethylene. Polym. Test. 2015, 44, 135-142. [CrossRef]

18. Bowler, N.; Liu, S. Aging Mechanisms and Monitoring of Cable Polymers. Progn. Health Manag. Soc. 2015, 6, 1-12.

19. Mustafa, E.; Afia, R.S.A.; Tamus, Z.A. Investigation of Electrical and Mechanical Properties of Low Voltage Power Cables under Thermal Stress. In Proceedings of the 2020 International Conference on Diagnostics in Electrical Engineering (Diagnostika), Pilsen, Czech Republic, 1-4 September 2020; pp. 1-4. [CrossRef]

20. Morsalin, S.; Phung, T.B.; Danikas, M.; Mawad, D. Diagnostic challenges in dielectric loss assessment and interpretation: A review. IET Sci. Meas. Technol. 2019, 13, 767-782. [CrossRef]

21. Lee, C.; Lee, K.-B. Radiation effects on dielectric properties of ethylene propylene rubber. J. Ind. Eng. Chem. 2008, 14, 473-479. [CrossRef]

22. Yizhou, Z.; Lei, W.; Pengyu, Z.; Liang, W.; Xuan, G.; Ge, T.; Huiming, M. Ageing Inspection for Cross-Linked Polyolefin Insulation Cable in NPP Using Dielectric Property. In Volume 1: Operations and Maintenance, Engineering, Modifications, Life Extension, Life Cycle and Balance of Plant; IEC, Digital Controls and Influence of Human Factors; American Society of Mechanical Engineers: New York, NY, USA, 2017; pp. 1-6.

23. Csányi, G.M.; Bal, S.; Tamus, Z.Á. Dielectric Measurement Based Deducted Quantities to Track Repetitive, Short-Term Thermal Aging of Polyvinyl Chloride (PVC) Cable Insulation. Polymers 2020, 12, 2809. [CrossRef] [PubMed]

24. Mustafa, E.; Afia, R.S.A.; Tamus, Z.Á. Condition Assessment of Low Voltage Photovoltaic DC Cables under Thermal Stress Using Non-Destructive Electrical Techniques. Trans. Electr. Electron. Mater. 2020, 21, 503-512. [CrossRef]

25. 62582-3-2012-IEC/IEEE International Standard-Nuclear Power Plants-Instrumentation and Control. Important to Safety-Electrical Equipment Condition Monitoring Methods_Part. 3 Elongation at Break; IEEE: Piscataway, NJ, USA, 2012; ISBN 978-0-7381-8088-5.

26. Gong, Y.; Hu, S.M.; Yang, X.L.; Fei, J.L.; Yang, Z.G.; Shi, X.Q.; Xie, Y.C.; Guo, A.H.; Xu, J.F. Comparative study on degradation of ethylene-propylene rubber for nuclear cables from gamma and beta irradiation. Polym. Test. 2017, 60, 102-109. [CrossRef]

27. Suraci, S.V.; Fabiani, D.; Mazzocchetti, L.; Giorgini, L. Degradation assessment of polyethylene-based material through electrical and chemical-physical analyses. Energies 2020, 13, 650. [CrossRef]

28. Menczel, J.D.; Prime, R.B. (Eds.) Thermal Analysis of Polymers: Fundamentals and Applications; Wiley: Hoboken, NJ, USA, 2009; ISBN 978-0-471-76917-0.

29. Jonscher, A.K. Dielectric relaxation in solids. J. Phys. D. Appl. Phys. 1999, 32, R57. [CrossRef]

30. Gillen, K.T.; Bernstein, R.; Clough, R.L.; Celina, M. Lifetime predictions for semi-crystalline cable insulation materials: I. Mechanical properties and oxygen consumption measurements on EPR materials. Polym. Degrad. Stab. 2006, 91, $2146-2156$. [CrossRef]

31. Gillen, K.T.; Celina, M.; Clough, R.L. Density measurements as a condition monitoring approach for following the aging of nuclear power plant cable materials. Radiat. Phys. Chem. 1999, 56, 429-447. [CrossRef]

32. Chailan, J.F.; Boiteux, G.; Chauchard, J.; Pinel, B.; Seytre, G. Effects of thermal degradation on the viscoelastic and dielectric properties of chlorosulfonated polyethylene (CSPE) compounds. Polym. Degrad. Stab. 1995, 48, 61-65. [CrossRef]

33. Mustafa, E.; Tamus, Á.Z.; Afia, R.S.A. Thermal Degradation and Condition Monitoring of Low Voltage Power Cables in Nuclear Power Industry. IFIP Adv. Inf. Commun. Technol. 2019, 553. [CrossRef]

34. Foucault, F.; Esnouf, S.; Le Moël, A. Irradiation/temperature synergy effects on degradation and ageing of chlorosulphonated polyethylene. Nucl. Instrum. Methods Phys. Res. Sect. B Beam Interact. Mater. Atom. 2001, 185, 311-317. [CrossRef] 
35. Boukezzi, L.; Rondot, S.; Jbara, O.; Boubakeur, A. A time-resolved current method and TSC under vacuum conditions of SEM: Trapping and detrapping processes in thermal aged XLPE insulation cables. Nucl. Instrum. Methods Phys. Res. Sect. B Beam Interact. Mater. Atoms 2017, 394, 126-133. [CrossRef]

36. Gillen, K.T.; Assink, R.; Bernstein, R.; Celina, M. Condition monitoring methods applied to degradation of chlorosulfonated polyethylene cable jacketing materials. Polym. Degrad. Stab. 2006, 91, 1273-1288. [CrossRef]

37. Calmet, J.F.; Carlin, F.; Nguyen, T.M.; Bousquet, S.; Quinot, P. Irradiation ageing of CSPE/EPR control command electric cables. Correlation between mechanical properties and oxidation. Radiat. Phys. Chem. 2002, 63, 235-239. [CrossRef]

38. Gillen, K.T.; Bernstein, R.; Celina, M. Non-Arrhenius behavior for oxidative degradation of chlorosulfonated polyethylene materials. Polym. Degrad. Stab. 2005, 87, 335-346. [CrossRef] 